ISSN 0717 - 2877

Universidad de Talca - Facultad de Ciencias Jurídicas y Sociales

Inclusión electoral de personas con discapacidad mental en Chile

Viviana Ponce de León Solís

Trabajo recibido el 13 de diciembre de 2018 y aprobado el 4 de diciembre de 2019

\title{
Inclusión electoral de personas con discapacidad mental en Chile
}

\author{
ELECTORAL INCLUSION OF PERSONS WITH MENTAL DISABILITIES IN CHILE
}

VIVIANA PONCE DE LEÓN SOLÍS

\begin{abstract}
RESUMEN
La inclusión electoral de personas con discapacidad mental es uno de los desafíos más complejos que enfrentan las democracias contemporáneas. El caso de estas personas presenta una serie de peculiaridades que dificultan de modo especial determinar lo que significa para ellas la ciudadanía y la participación política. A diferencia de otros grupos tradicionalmente marginados -como niños, niñas y adolescentes o personas con discapacidades físicas-, ciertas personas con discapacidad mental carecen de forma total y permanente de las habilidades típicamente asociadas con el derecho a sufragio. Así, esta investigación discute por qué deberíamos preocuparnos por la inclusión electoral de personas con discapacidad mental y qué posibles vías existen para lograr que dicha inclusión se traduzca en algún grado de participación política significativa. Para tal efecto, se centra en dos instituciones propias del derecho electoral chileno: la suspensión del sufragio de personas declaradas en interdicción por demencia y el voto asistido.
\end{abstract}

\section{ABSTRACT}

Electoral inclusion of people with mental disabilities is one of the most complex challenges contemporary democracies face. These people's case presents a series of peculiarities that make especially difficult to determine what citizenship and political participation mean to them. Unlike other traditionally marginalized groups -such as children and teenagers or people with physical disabilities-, certain people with mental disabilities totally and permanently lack the capabilities typically associated with the right to vote. Thus, this research argues why we should worry about the electoral inclusion of people with mental disabilities and what are the possible ways to make that inclusion translate into some degree of meaningful political participation. To that effect, it focuses on two characteristic institutions of Chilean electoral law: the suspension of voting rights of people placed under guardianship and assisted vote.

\section{PALABRAS CLAVE}

Derecho de voto, personas con discapacidad, capacidad jurídica, capacidad electoral, voto asistido.

\section{KEY WORDS}

Right to vote, persons with disabilities, legal capacity, electoral capacity, assisted vote.

\footnotetext{
* Profesora Auxiliar de la Facultad de Ciencias Jurídicas y Sociales de la Universidad Austral de Chile (sede Puerto Montt) e investigadora del Núcleo de Interdisciplinario sobre Desigualdad y Derechos Humanos (DesDeH) de la Universidad Austral de Chile. Dirección postal: Escuela de Derecho, Universidad Austral, Los Pinos s/n, Balneario Pelluco, Puerto Montt, Chile. Correo electrónico: viviana.poncedeleon@uach.cl. ID ORCID: https://orcid.org/0000-0001-7574-1717.
} 


\section{Introducción}

Se ha dicho que la plena inclusión democrática de personas con discapacidad mental ${ }^{1}$ representa "una de las más importantes luchas ciudadanas de las décadas recientes"2, "el último movimiento sufragista" ${ }^{3}$, "una batalla más en el proceso de normalización" ${ }^{4}$ y "la bomba de tiempo del electorado" ${ }^{5}$. A pesar de que por mucho tiempo este tópico ha sido sub-teorizado y escasamente problematizado en la literatura filosófica, jurídica y política, en las últimas décadas se ha podido observar una creciente tendencia en el sentido inverso. Así, puede observarse, por ejemplo, en el marco del debate académico sobre la inclusión democrática de personas privadas de libertad, de niños, niñas y adolescentes e incluso de animales ${ }^{6}$. La discusión es importante no solo porque contribuye a promover la autonomía de un grupo particularmente vulnerable, sino además porque revela las debilidades estructurales del sistema democrático y los prejuicios sociales en que dichas debilidades se sustentan.

En Chile, las personas con discapacidad mental gozan formalmente del estatus de ciudadanas y, en principio, están habilitadas para ejercer el derecho de sufragio. En este país, fuera del reconocimiento constitucional de una serie de derechos fundamentales que se aseguran a toda persona, se cuenta con normativa dirigida a establecer medidas contra la discriminación y a promover la inclusión de personas con discapacidad mental. Además, se han ratificado diversos instrumentos internacionales con el mismo propósito. $Y$, sin embargo, existe una serie de factores jurídicos y materiales que determinan la exclusión de las personas con discapacidad mental y su relegación fáctica a una ciudadanía de segunda clase. Ello se debe a que dichos factores operan como obstáculos o impedimentos para su participación democrática y, en particular, para el ejercicio de su derecho a sufragio.

Conviene destacar que, aunque la participación no se agota en el derecho a sufragio, este sigue siendo visto como el signo más distintivo del estatus ciudadano y como el mecanismo de participación por excelencia, al punto de ser visto como "el derecho de los derechos"7. De ahí que la presente investigación se centre en dos instituciones vigentes en el derecho chileno que tienen un impacto directo en el alcance del derecho a sufragio de las personas con discapacidad mental. Esas instituciones corresponden a la suspensión del derecho de sufragio de personas declaradas en interdicción por demencia y el voto asistido, con particular atención en las facilidades materiales que se otorgan a los electores con discapacidades. El análisis de una y otra tiene por objeto

\footnotetext{
${ }^{1}$ Aunque el punto no es enteramente pacífico, en la literatura sobre discapacidad es habitual que se distinga entre discapacidad intelectual, cognitiva y psicosocial. La primera implica que una persona tiene "más dificultad que la mayoría de las personas con su funcionamiento intelectual y adaptativo, debido a una condición de largo plazo que está presente en el nacimiento o antes de la edad de dieciocho años". La segunda afecta igualmente el funcionamiento intelectual y adaptativo de las personas, "generalmente con un inicio posterior a los dieciocho años, pero que puede resultar de una lesión cerebral de una edad previa" y comprende condiciones como demencia o mal de Alzheimer, entre otras. La tercera, por último, se asocia a "problemas de salud mental" e incluye a usuarios de servicios de salud mental o sobrevivientes de abusos por prácticas psiquiátricas. BACH Y KERZNER (2010), pp. 14-15. Dado que, según se explicará en el apartado 2 de este texto, la noción de "demencia" como fundamento de la declaración de interdicción y de la suspensión del derecho a sufragio tiene un alcance amplio, en este texto se utilizará la expresión "discapacidad mental" para hacer referencia a la discapacidad intelectual, cognitiva y psicosocial.

2 "One of the most important citizenship struggles in recent decades has focused on people with cognitive disabilities". DONALDSON Y KYMLICKA (2017), p. 168.

${ }^{3}$ SCHRINER et al. (1997).

4 "[T]he recognition of voting rights is one more battle in the process of normalization". BELL et al. (2001), p. 122.

5 "People with disabilities are the ticking time bomb of the electorate". BELT (2016), p. 1491.

${ }^{6}$ BECKMAN (2009); DONALDSON Y KYMLICKA (2017); LOPEZ-GUERRA (2014); LOPEZ-GUERRA (2012).

${ }^{7}$ WALDRON (1998).
} 
determinar en qué medida Chile se aproxima —o se aleja - del ideal de inclusión democrática, en línea con los compromisos internacionales que ha contraído.

Para tal efecto, este texto se divide en seis secciones. En la primera sección se presenta el marco normativo internacional y nacional vigente en la materia, destacando las principales normas que consagran el derecho de participación política de las personas con discapacidades en general. En la segunda sección se expone brevemente el sistema chileno de declaración de interdicción por demencia como fundamento de la suspensión del derecho a sufragio de las personas con discapacidad mental. En la tercera y cuarta sección se identifican los principales argumentos a favor y en contra de la exclusión electoral de dichas personas, respectivamente. En la quinta sección se describe cómo han evolucionado los sistemas de subordinación de la capacidad electoral a las declaraciones generales de capacidad jurídica a nivel comparado. En la sexta sección, por último, se sostiene que, pese a la creciente tendencia en orden a promover la inclusión democrática de las personas con discapacidad mental, subsisten una serie de obstáculos fácticos al ejercicio de su derecho a voto, aun en su modalidad de voto asistido.

\section{Marco normativo}

Una serie de instrumentos internacionales asegura ciertos derechos políticos a todas las personas, incluyendo el derecho a voto en elecciones periódicas auténticas realizadas por sufragio universal e igualitario y por voto secreto que garantice la libre expresión de la voluntad de los electores. Así puede verse en los artículos 21.3 de la Declaración Universal de Derechos Humanos $(\mathrm{DUDH})^{8}$, 25.a del Pacto Internacional de Derechos Civiles y Políticos (PIDCP) ${ }^{9}$ y 23.1.b de la Convención Americana sobre Derechos Humanos $(C A D H){ }^{10}$. Sin embargo, estos mismos instrumentos contemplan la posibilidad de imponer restricciones legítimas al ejercicio de estos derechos. Por ejemplo, el art. 25 PIDCP reconoce que "[t]odos los ciudadanos gozarán, sin ninguna de las distinciones mencionadas en el artículo 2 [entre las que no está, por cierto, la discapacidad], y sin restricciones indebidas". A su vez, el art. 23.2 CADH establece que "[I]a ley puede reglamentar el ejercicio de los derechos y oportunidades a que se refiere el inciso anterior, exclusivamente por razones de edad, nacionalidad, residencia, idioma, instrucción, capacidad civil o mental, o condena, por juez competente, en proceso penal".

A estos instrumentos se han sumado otros más recientes específicamente referidos a la inclusión de personas con discapacidad. Entre ellos cabe destacar los Principios para la Protección de los Enfermos Mentales y el Mejoramiento de la Atención de la Salud Mental ${ }^{11}$, que establecen que

[t]odas las personas que padezcan una enfermedad mental tendrán derecho a ejercer todos los derechos civiles, políticos, económicos, sociales y culturales reconocidos en la Declaración Universal de Derechos Humanos, el Pacto Internacional de Derechos Económicos, Sociales y Culturales, el Pacto Internacional de Derechos Civiles y Políticos y otros instrumentos pertinentes, tales como la Declaración de los Derechos de los Impedidos y el Conjunto de Principios para la protección de todas las personas sometidas a cualquier forma de detención o prisión.

\footnotetext{
${ }^{8}$ Resolución 217 A (III), de 1948.

${ }^{9}$ Resolución 2200 A (XXI), de 1966.

${ }^{10}$ Decreto № 873, de 1991.

${ }^{11}$ Resolución 46/119, de 1991.
} 
Del mismo modo, puede mencionarse la Convención Americana para la Eliminación de Todas las Formas de Discriminación contra las Personas con Discapacidad de la OEA ${ }^{12}$. De acuerdo con el art. III.a de esta Convención, los Estados partes asumen el compromiso de adoptar las

[m]edidas para eliminar progresivamente la discriminación y promover la integración por parte de las autoridades gubernamentales y/o entidades privadas en la prestación o suministro de bienes, servicios, instalaciones, programas y actividades, tales como el empleo, el transporte, las comunicaciones, la vivienda, la recreación, la educación, el deporte, el acceso a la justicia y los servicios policiales, y las actividades políticas y de administración.

Con todo, el instrumento más relevante en esta materia es, sin duda alguna, la Convención de las Naciones Unidas sobre los Derechos de las Personas con Discapacidad (CNUDPD) ${ }^{13}$. Su art. 29, referido a la participación en la vida política y pública, impone a los Estados partes el deber de "garantizar [] a las personas con discapacidad los derechos políticos y la posibilidad de gozar de ellos en igualdad de condiciones con las demás". Para ello, conforme a la letra a) del mismo artículo, los Estados partes deberán

[a]segurar que las personas con discapacidad puedan participar plena y efectivamente en la vida política y pública en igualdad de condiciones con las demás, directamente o a través de representantes libremente elegidos, incluidos el derecho y la posibilidad de las personas con discapacidad a votar y ser elegidas.

La disposición precisa de manera no taxativa los mecanismos mediante los cuales se puede satisfacer este deber. En primer lugar, se establece "[l]a garantía de que los procedimientos, instalaciones y materiales electorales sean accesibles y fáciles de entender y utilizar". En segundo lugar, se consagra "[l]a protección del derecho de las personas con discapacidad a emitir su voto en secreto en elecciones y referéndum públicos sin intimidación". Y, en tercer lugar, se consagra "[I]a garantía de la libre expresión de la voluntad de las personas con discapacidad como electores y a este fin, cuando sea necesario y a petición de ellas, permitir que una persona de su elección les preste asistencia para votar".

Junto con estos instrumentos, a nivel interno, el art. 10 inc. $1^{\text {O }}$ de la Constitución Política de la República de Chile ${ }^{14}$ (CPR) establece que "[t]odas las personas nacen libres e iguales en dignidad y derechos". Esta declaración a su vez se proyecta en el art. 1ㅇinc. 5 CPR, disposición que impone al Estado el deber de "promover la integración armónica de todos los sectores de la Nación y asegurar el derecho de las personas a participar con igualdad de oportunidades en la vida nacional". Por su parte, el art. 19 № 2 CPR asegura a todas las personas la igualdad ante la ley.

En concreción de los preceptos constitucionales transcritos, la Ley № 20.609 que establece medidas contra la discriminación ${ }^{15}$, define como discriminación arbitraria

toda distinción, exclusión o restricción que carezca de justificación razonable, efectuada por agentes del Estado o particulares, y que cause privación, perturbación o amenaza en el ejercicio legítimo de los derechos fundamentales establecidos en la Constitución Política de la República o en los tratados

\footnotetext{
${ }^{12}$ Decreto № 99, de 2002.

${ }^{13}$ Decreto № 201, de 2008.

${ }^{14}$ Decreto № 100, de 2005.

${ }^{15}$ Ley № 20.609, de 2012.
} 
internacionales sobre derechos humanos ratificados por Chile y que se encuentren vigentes, en particular cuando se funden en motivos tales como la [...] discapacidad.

Para dotar de operatividad a esta disposición, los arts. 3 a 14ㅇ de la ley contemplan una acción especial de no discriminación arbitraria.

Finalmente, resulta pertinente mencionar también la Ley № 20.422 que establece normas sobre igualdad de oportunidades e inclusión social de personas con discapacidad ${ }^{16}$. De acuerdo con su art. 1으, se asegura a estas "el derecho a la igualdad de oportunidades [...], con el fin de obtener su plena inclusión social, asegurando el disfrute de sus derechos y eliminando cualquier forma de discriminación fundada en la discapacidad". Para estos efectos, según el art. 700 de la ley, la igualdad de oportunidades se entiende como

la ausencia de discriminación por razón de discapacidad, así como la adopción de medidas de acción positiva orientadas a evitar o compensar las desventajas de una persona con discapacidad para participar plenamente en la vida política, educacional, laboral, económica, cultural y social.

\section{Capacidad jurídica y capacidad electoral de las personas con discapacidad mental}

En Chile, de acuerdo con lo dispuesto en el art. 16 № 1 de la CPR, una de las causales en virtud de las que se puede suspender el derecho a sufragio de un ciudadano es la interdicción en caso de demencia. Esto significa que la capacidad electoral de las personas con discapacidad mental se encuentra subordinada a una declaración general de incapacidad que se materializa en un procedimiento de declaración de interdicción por demencia. Dicho procedimiento tiene por objeto privar a una persona de la administración de sus bienes, en la medida que se encuentre en un estado habitual de "demencia", y disponer el nombramiento de un curador para tal efecto. El mismo se encuentra regulado en los arts. 456 y siguientes del Código Civil ${ }^{17}$ (CC), en los arts. 838 y siguientes del Código de Procedimiento $\mathrm{Civil}^{18}$ (solo en cuanto al nombramiento de curador) y en la Ley № 18.600 que establece normas sobre deficientes mentales ${ }^{19}$.

La declaración de interdicción admite dos vías de inicio, según la discapacidad se halle o no calificada y certificada. Según el art. 13 de la Ley № 20.422, tal acto corresponde a las Comisiones de Medicina Preventiva e Invalidez (COMPIN) y a las instituciones públicas o privadas reconocidas para estos efectos por el Ministerio de Salud. La certificación de la discapacidad, a su vez, es de exclusiva competencia de las COMPIN. Tanto la calificación como la certificación podrán efectuarse a petición del propio interesado, de las personas que lo representen, o de las personas o entidades que lo tengan a su cargo. El art. 17 de la ley agrega que, una vez certificada la discapacidad, los antecedentes respectivos deberán ser remitidos al Servicio de Registro Civil e Identificación, para su inscripción en el Registro Nacional de la Discapacidad. El art. 4ㅇ de la Ley № 18.600 complementa estas normas indicando que, cuando la discapacidad mental de una persona ha sido inscrita en el Registro, su padre o madre puede solicitar al juez que, previa audiencia de la persona con la discapacidad, decrete la interdicción definitiva y le nombre un curador de sus bienes. En tal supuesto, el objeto del procedimiento no será la acreditación de la "demencia", sino la sola declaración de interdicción de la persona inscrita.

\footnotetext{
${ }^{16}$ Ley $\mathrm{N}^{\circ} 20.422$, de 2010.

${ }^{17}$ DFL № 1 , de 2000.

${ }^{18}$ Ley № 1.552 , de 1902.

${ }^{19}$ Ley № 18.600 , de 1987.
} 
Por el contrario, si la discapacidad no está inscrita en el Registro Nacional de la Discapacidad, se deberá seguir el procedimiento establecido en el CC, que consiste en un juicio ordinario de interdicción. Por consiguiente, en este caso se interpone una demanda de interdicción ante el juzgado civil dentro de cuya jurisdicción esté ubicado el domicilio del demandante. Se hallan legitimados para provocar la interdicción del supuesto demente: la persona que ejerce la curaduría del o la menor a quien sobreviene la demencia durante la curaduría, su cónyuge no separado judicialmente, cualquiera de sus consanguíneos hasta el cuarto grado o el Defensor Público. Este último deberá ser oído incluso en los casos en que él no hubiere provocado el juicio. Además, conforme al art. 460 del CC, si la "locura fuere furiosa, o si el loco causare notable incomodidad a los habitantes, podrá también el procurador de ciudad o cualquiera del pueblo provocar la interdicción". A fin de probar la demencia, el art. 460 CC alude a informes sobre la vida anterior y la conducta habitual del juez, así como a informes periciales médicos "sobre la existencia y naturaleza de la demencia".

Respecto de quienes se ven afectados por este procedimiento, ni el constituyente ni el legislador han definido cómo debe interpretarse la expresión "demencia". Sin embargo, en doctrina y jurisprudencia nacional se le entiende en un sentido amplio, comprensivo de todo tipo de "enajenación mental" ${ }^{20}$ o "trastorno de la razón que impide a una persona tener la libre voluntad de obligarse y la responsabilidad de sus actos haciéndolo absolutamente incapaz" ${ }^{21}$. En una formulación alternativa, demente sería "aquella persona que, como consecuencia de una enfermedad mental, carece de la aptitud necesaria para administrar competentemente lo suyo" 22 . A la luz de estas definiciones, la categoría jurídica de demente comprende en bloque a una serie de condiciones mentales, entre las que se incluyen: síndrome de Down, paranoia, psicosis, esquizofrenia, estado vegetativo persistente, alzhéimer, trastorno bipolar, trastornos del espectro autista, etc.

En cuanto a los efectos de la declaración de interdicción, estos son fundamentalmente de índole patrimonial. Es así como la persona declarada en interdicción queda, en general privada de la administración de sus bienes, la cual pasa a ser ejercida por su curador. En consecuencia, se les considera inhábiles para testar ${ }^{23}$, para ser testigos en un testamento ${ }^{24}$, para repudiar su reconocimiento, salvo por medio de su curador y contando este con autorización judicial ${ }^{25}$, para celebrar un contrato de trabajo personalmente ${ }^{26}$, etc. A todas estas inhabilidades, paradójicamente, se suma también una de carácter no patrimonial que corresponde a la suspensión de su derecho a sufragio, la cual fue aludida al inicio de este apartado.

Como se puede apreciar, la legislación chilena vigente en materia de capacidad jurídica de las personas con discapacidad mental obedece a un paradigma radicalmente distinto de aquel que inspira los instrumentos internacionales sobre el particular ${ }^{27}$. Así, la normativa nacional se enmarca en el modelo médico de discapacidad, conforme al cual la discapacidad es vista como un problema

\footnotetext{
${ }^{20}$ CLARO (1992), p. 100.

${ }^{21}$ CLARO (1992), p. 103.

22 LYON (2007), p. 179.

${ }^{23}$ Art. 1005 № 3 CC.

${ }^{24}$ Art. 1012 № 3 CC.

${ }^{25}$ Art. 191 inc. 2으.

${ }^{26}$ Art. 16 Ley № 18.600, de 1987.

${ }^{27}$ La literatura sobre modelos de discapacidad es bastante abundante y un análisis pormenorizado de la misma excede con creces el propósito de este trabajo, por lo que me limito a señalar que son referencias obligadas en esta materia, entre otras, FINKELSTEIN (1980), LLEWELYN Y HOGAN (2000), MARKS (1998) y OLIVER (1990). En torno a la evolución de estos modelos y a la posición que entre ellos le correspondería a la normativa nacional sobre discapacidad, véase SILVA (2017), pp. 25-39. Sobre otras contradicciones, en general, entre la legislación chilena y la CNUDPD, véase COMITÉ SOBRE LOS DERECHOS DE LAS PERSONAS CON DISCAPACIDAD (2016) y SILVA (2017).
} 
médico que se expresan en limitaciones físicas, psíquicas o sensoriales del individuo que las padece. Bajo este modelo, la discapacidad es un problema individual cuya solución es la rehabilitación o normalización. Por contraste, los instrumentos internacionales sobre derechos de las personas con discapacidad se encuadran en el modelo social de la discapacidad, de acuerdo con el cual las causas de la discapacidad no son individuales, sino sociales. En otras palabras, hay ciertas limitaciones estructurales que la sociedad impone a las personas con discapacidad, que les impiden el pleno goce de sus derechos y el acceso a servicios básicos.

No es de extrañar, entonces, que pese a su amplia aplicación ${ }^{28}$, la regulación vigente en materia de discapacidad mental y declaración de interdicción por demencia ha sido blanco de múltiples críticas. Para empezar, se ha cuestionado el que la declaración judicial de interdicción pueda verificarse con el solo mérito de la certificación de discapacidad e inscripción en el Registro Nacional de Discapacidad, en una suerte de sublimación del modelo médico de discapacidad ${ }^{29}$. Del mismo modo, se reprocha que se pueda proceder a la designación de un curador de bienes cumpliendo requisitos mínimos y que este sustituya la voluntad de la persona declarada en interdicción, en vez de apoyarla ${ }^{30}$. $Y$, por fin, se observa que en ninguna de las normas citadas se reconoce expresamente la capacidad jurídica de las personas con discapacidad mental ${ }^{31}$, apreciación que se ve confirmada por la existencia de una serie de restricciones dispersas en el Código Civil a la capacidad jurídica de los "dementes", que no están subordinadas a su declaración de interdicción por demencia.

Con todo, los efectos electorales que se asignan a la declaración de interdicción por demencia prácticamente no han sido objeto de discusión ${ }^{32}$. Lo anterior resulta sorprendente si se toma en cuenta el mandato que la CNUDPD impone a sus Estados partes, quienes "garantizarán a las personas con discapacidad los derechos políticos y la posibilidad de gozar de ellos en igualdad de condiciones con las demás". Por ello es que los próximos apartados se destinan al análisis de los principales argumentos que se esgrimen a favor y en contra de la exclusión electoral y al estudio de la situación a nivel comparado.

\section{Argumentos en favor de la exclusión electoral de las personas con discapacidad mental}

En general, como se señaló, la disposición del art. 16 № 1 CPR no ha dado lugar a mayores cuestionamientos o debates en la literatura académica nacional, lo cual sugiere que se da por supuesto que la limitación que contiene es justificada. A lo más, algo de discusión se dio en el marco de la Comisión de Estudios de la Nueva Constitución de 1980 (CENC) cuando se acordó la redacción de la disposición en comento. Sin embargo, en ella, la cuestión a resolver no era precisamente la legitimidad de la limitación, sino más bien la fórmula bajo la cual la misma debía enunciarse a fin de evitar abusos. Y no es de extrañar que sea así. Después de todo, la exclusión electoral de las personas con discapacidad mental es una idea sumamente arraigada en el pensamiento político clásico, moderno y contemporáneo ${ }^{33}$. En este contexto es que se articulan argumentos de diversa índole que permiten dar sustento a esta práctica.

\footnotetext{
${ }^{28}$ GONZÁLEZ (2018), pp. 101-102.

29 DEPARTAMENTO DE EVALUACIÓN DE LA LEY. CÁMARA DE DIPUTADOS DE CHILE (2013), p. 18.

${ }^{30}$ DEPARTAMENTO DE EVALUACIÓN DE LA LEY. CÁMARA DE DIPUTADOS DE CHILE (2013), p. 18

${ }^{31}$ DEPARTAMENTO DE EVALUACIÓN DE LA LEY. CÁMARA DE DIPUTADOS DE CHILE (2013), p. 18. Idéntico cuestionamiento es formulado en DEPARTAMENTO DE EVALUACIÓN DE LA LEY. CÁMARA DE DIPUTADOS DE CHILE (2012), p. 24.

${ }^{32}$ Constituyen notables excepciones a la regla general, GONZÁLEZ (2018) y MARSHALL (2019).

${ }^{33}$ SCHRINER et al. (2000), pp. 447-451.
} 
La primera categoría de argumentos que suele esgrimirse para justificar la exclusión electoral de personas con discapacidad mental es que ellas carecen de la capacidad para adoptar decisiones racionales. Desde esta perspectiva, se asume que estas personas no son capaces de comprender el valor del acto de votar y sus implicancias, de manera que su participación en democracia no tendría sentido ${ }^{34}$. Esta idea ha sido aceptada por la doctrina nacional acríticamente y sin mayor desarrollo. Así, por ejemplo, Silva Bascuñán observa que

[s]iendo el sufragio un derecho, cuyo ejercicio interesa y compromete a toda la colectividad, presupone una indiscutible actuación plenamente racional de quien hace uso de él, de la que cabe estimar carece la persona que, mediante sentencia judicial firme, ha sido declarada en interdicción por demencia ${ }^{35}$.

Del mismo modo, Nogueira afirma que

[l]a fundamentación de tal suspensión está dada por el hecho de que el ejercicio de sufragio consiste en un acto de carácter racional y reflexivo que exige la plenitud de las facultades mentales, situación en la que no se encuentra quien ha sido declarado en interdicción por causa de demencia ${ }^{36}$.

Siguiendo el hilo de estas inquietudes, una segunda clase de argumentos alude a la necesidad de restringir la participación electoral únicamente a un electorado "educado", "instruido" o "inteligente" y de evitar resultados electorales subóptimos ${ }^{37}$. A esta clase de argumentos subyace la presunción de que las personas con discapacidad mental tenderían a escoger de manera sistemática las peores opciones disponibles en la papeleta de votación. En este sentido, por ejemplo, podrían votar por personas proclives a abusar de su poder para obtener un beneficio personal, votar al azar o reaccionar impulsivamente frente a ofertas electorales populistas peligrosas ${ }^{38}$. El punto no sería menor si se considera que, no obstante su carácter minoritario, desde un punto de vista numérico, el voto de las personas con discapacidad mental podría incidir decisivamente en los resultados de una elección ${ }^{39}$.

El tercer grupo de argumentos sostiene que la exclusión electoral de personas con discapacidad mental se justifica en la preservación de la integridad, justicia o pureza del proceso electoral, de manera que este no se vea afectado por factores que comprometan su legitimidad ${ }^{40}$. Más concretamente, aquello que podría comprometer la legitimidad de los procesos electorales en que participen personas con discapacidad mental sería un eventual quiebre de la igualdad política, entendida como igual distribución de la influencia política entre los ciudadanos. En efecto, la participación de estos en el ejercicio del poder político por medio de su voto se funda en su capacidad de autodeterminación respecto de las leyes y las personas que les gobiernan ${ }^{41}$. Las personas que carecen de tal capacidad y dependen de otros para expresar su voluntad o comprender el proceso electoral mismo corren el riesgo de ser influenciadas, manipulados o coaccionadas por quienes les proporcionan cuidados o les asisten. Siendo así ciertamente se podría

\footnotetext{
${ }^{34}$ COHEN (1975), p. 460.

${ }^{35}$ SILVA (1997), p. 257.

${ }^{36}$ NOGUEIRA (2012), p. 791.

${ }^{37}$ KOPEL (2017), p. 227; REDLEY et al. (2012), p. 1027.

${ }^{38}$ LOPEZ-GUERRA (2014), p. 66.

${ }^{39}$ AGRAN et al. (2015), p. 58; LOPEZ-GUERRA (2014), p. 65.

${ }^{40}$ APPELBAUM et al. (2005), p. 850; LOPEZ-GUERRA (2014), pp. 75-77.

${ }^{41}$ DAHL (1992), p. 158; LOCKE (2006), pp. 62-63.
} 
terminar por asignar a estos últimos una cuota mayor de influencia política que la que le corresponde al resto de los ciudadanos en el proceso electoral ${ }^{42}$.

Finalmente, un cuarto tipo de argumentos apunta al modo en que la inclusión electoral de personas con discapacidad mental incidiría en la percepción del público acerca de su propia participación política y de la seriedad de los procesos electorales en general. Un autor lo plantea en la siguiente forma:

¿por qué valdría la pena pasar tiempo analizando las opciones en la papeleta, un votante competente podría preguntar, si el Estado está dispuesto a permitir participar incluso a personas claramente incompetentes en lo que uno podría concluir que es un proceso no terriblemente importante? ${ }^{43}$

Nótese que este último argumento no alude a un daño concreto a los propios votantes con discapacidades mentales ni al potencial impacto de su participación en el resultado de la elección, sino al daño simbólico al proceso electoral y a la democracia misma ${ }^{44}$. La siguiente cita del comisionado Ovalle, en la sesión 75 del 03 de octubre de 1974 CENC refleja esta idea: "el propósito del constituyente es darle al proceso electoral una seriedad y una 'pristineidad', - si el término es correcto-, que deben ser educadoras para el futuro" ${ }^{45}$. En el mismo sentido, y en la misma oportunidad, el comisionado Silva hizo presente que

la Constitución tiene un aspecto didáctico, de educación cívica, y es indispensable poner de relieve todo aquello que manifieste la seriedad del proceso político. Es enormemente conducente a ello la circunstancia de que la Constitución recoja que quien tenga esas limitaciones no puede ejercer el derecho de sufragio ${ }^{46}$.

\section{Argumentos en contra de la exclusión electoral de las personas con discapacidad mental}

Pese a que los argumentos en favor de la exclusión electoral de las personas con discapacidad siguen constituyendo la visión mayoritaria o predominante, en los últimos años se ha desarrollado un creciente cuerpo de literatura que defiende la postura opuesta. De acuerdo con el mismo, las inquietudes doctrinarias relativas a la carácter irracional, caprichoso, manipulable y dañino de la participación electoral de estas personas obedece a prejuicios o falsas representaciones históricamente asentadas ${ }^{47}$. Por consiguiente, quienes encarnan esta corriente de pensamiento procuran proporcionar evidencia empírica que permita derrotar los argumentos tradicionales y desarrollan explicaciones teóricas alternativas que los reemplacen. Mediante esta estrategia se aspira a lograr resultados más consistentes con la promoción de la autodeterminación y con la inclusión de personas con discapacidad mental ${ }^{48}$.

\footnotetext{
${ }^{42}$ BECKMAN (2009), p. 156.

43 "Why is it worth spending time analyzing the choices on the ballot, a competent voter might ask, when the state is willing to allow even clearly incompetent people to participate in what one might conclude is not a terribly important process?". HURME Y APPELBAUM (2007), p. 964.

44 "Some believe that voting is an important civic duty, one that underpins the value of democracy when done in an informed and conscientious manner. It looks like we are openly admitting that it is not important to vote in an informed and conscientious manner if we accept a system where it is possible for some people without capacity to vote". BARCLAY (2013), p. 157.

${ }^{45} \mathrm{BCN}$ (s. f.), p. 31.

${ }^{46} \mathrm{BCN}$ (s. f.), p. 27.

${ }^{47}$ GREEN Y KLEIN (1980), p. 205

${ }^{48}$ AGRAN Y HUGHES (2013), p. 394.
} 
Así las cosas, respecto de la capacidad para tomar decisiones racionales, se plantea que no existen parámetros que permitan distinguir categóricamente a un votante irracional de un votante racional ${ }^{49}$. De esta manera, cualquiera sea el parámetro que se emplee, siempre existe la posibilidad de sobre-inclusión o de sub-inclusión ${ }^{50}$. Mas, habida cuenta que las personas con discapacidad mental pertenecen a un grupo vulnerable, que la discapacidad es una categoría sospechosa de discriminación y que la privación del derecho a sufragio es una de las medidas más severas que puede imponerse en democracia, parece conveniente errar en el sentido de la sobre-inclusión. Por lo demás, aun de demostrarse la incapacidad electoral de estas personas, "debe recordarse que buena parte de la votación es altamente irracional, incluso entre personas de capacidad intelectual normal" 51 . De hecho, como lo demuestran los estudios comparados sobre el voto en blanco y nulo, no es inusual que los votantes presuntamente capaces emitan sus votos basándose en consideraciones irracionales o incurriendo en error ${ }^{52}$.

En cualquier caso, y ahora específicamente respecto de los efectos electorales que conlleva una declaración general de incapacidad jurídica, ha de puntualizarse que las capacidades son específicas para cada tarea ${ }^{53}$. En consecuencia, la capacidad para celebrar un contrato, para testar o en general para ejecutar actos jurídicos de contenido patrimonial no es la misma capacidad que se requiere para tomar parte en un proceso electoral ${ }^{54}$. Sin embargo, el procedimiento de interdicción por demencia no está diseñado para medir específicamente las competencias necesarias para formarse una preferencia electoral, para comprender el sentido y valor del voto o para simplemente expresarse como votante. Más todavía, según se expuso más arriba, la calidad de demente comprende en bloque a todas las formas de discapacidad mental, "sin reconocer diferencias y sin que se prevea la posibilidad de autonomía o capacidad progresiva para cada caso" 55 .

De otro lado, frente al argumento sobre el supuesto riesgo de que el voto de personas con discapacidad mental comprometa los resultados del proceso electoral, cabe formular un profundo cuestionamiento. En efecto, existen numerosos estudios empíricos que sugieren lo contrario ${ }^{56}$. Algunos de ellos concluyen que las preferencias de estas personas no difieren proporcionalmente de las del resto de la población ${ }^{57}$. Otros, arrojan como resultado que, con instrucción sistemática, aquellas pueden tomar decisiones electorales informadas ${ }^{58}$. Finalmente, ciertas investigaciones indican que sus preferencias electorales coinciden con las posiciones políticas que razonablemente podría esperarse que asuman dada su situación ${ }^{59}$. Sin perjuicio de lo anterior, es sumamente discutible que entre las alternativas disponibles en un régimen democrático existan preferencias o resultados electorales mejores o peores ${ }^{60}$. Después de todo, si se considera que un determinado partido o candidato representa posturas políticas suficientemente razonables como para competir

\footnotetext{
${ }^{49}$ KOPEL (2017), p. 224.

${ }^{50}$ KOPEL (2017), p. 224; BECKMAN (2014), pp. 224-225.

51 "[ I] should be remembered that much of voting is highly irrational even among persons of normal intellectual capacity". WALD (1976), p. 25.

52 DAMORE et al. (2012), pp. 895-907; DRISCOLL Y NELSON (2014), pp. 1-15.

${ }^{53}$ BHUGRA et al. (2016), p. 3.

${ }^{54}$ OKWEREKWU et al. (2018), p. 3.

${ }^{55}$ DEPARTAMENTO DE EVALUACIÓN DE LA LEY. CÁMARA DE DIPUTAdOS DE CHILE (2013), p. 19.

${ }_{56}$ Una visión panorámica de los resultados de diversos estudios empíricos conducidos para evaluar la capacidad de las personas con discapacidad mental para tomar decisiones electorales puede verse en BHUGRA et al. (2016), p. 4 y REDLEY (2008), p. 380.

${ }^{57}$ KELLY (2014); KLEIN (1971).

${ }^{58}$ REDLEY et al. (2012), p. 1031.

${ }^{59}$ BULLENKAMP Y VOGES (2004), pp. 1440-1442.

${ }^{60}$ LOPEZ-GUERRA (2014), p. 66.
} 
en una elección, debería también considerarse suficientemente razonable la emisión de un voto a su favor ${ }^{61}$.

Adicionalmente, en lo concerniente a las inquietudes relativas a un quiebre de la igualdad política y a los peligros de manipulación, cabe hacer dos alcances. Primero, aunque existe un interés legítimo en que los votantes expresen preferencias electorales independientes que reflejen sus genuinos intereses, no existen criterios que permitan distinguir claramente entre preferencias electorales dependientes e independientes ${ }^{62}$. Las preferencias de los electores son vulnerables frente a una serie de factores que influyen, a veces decisivamente, en su contenido. En consecuencia, la ausencia de un acto de manipulación en sentido técnico no necesariamente garantiza la independencia de la preferencia manifestada ${ }^{63}$. Segundo, incluso si fuese efectivo que una persona con discapacidades mentales es más susceptible a la manipulación electoral que otros ciudadanos, entonces puede afirmarse que esa persona no goza de oportunidades efectivas de participación en democracia. El punto es importante porque el deber de respetar y promover la inclusión democrática recae sobre los propios participantes del proceso democrático ${ }^{64}$. Si bien es cierto que la manipulación puede ocurrir, ello no justifica penalizar a la misma persona con discapacidades privándole de su derecho a voto, sobre todo si el fundamento de tal penalización radica en la conducta de una tercera persona ${ }^{65}$.

En línea con lo anterior, los argumentos que versan sobre un potencial daño simbólico al proceso electoral y a la democracia deben ser tratados con extremo recelo. En primer lugar, no existe evidencia publicada que dé sustento a estos temores. Como segunda cuestión, la exclusión electoral de las personas con discapacidad mental vigente en la mayoría de los Estados tampoco ha conducido a los votantes presuntamente capaces a aproximarse a los procesos electorales con más seriedad $^{66}$. Al contrario, lo que se observa en la generalidad de las democracias contemporáneas es una severa crisis de alienación política, manifestada en un creciente declive de las tasas de participación política. Queda así de manifiesto que el valor del voto en cuanto deber cívico de la mayor importancia solo se ve puesto en entredicho en la medida que se incluya a personas con discapacidad mental ${ }^{67}$. Dado este contexto, no cabe sino admitir que esta clase de argumentos se funda únicamente en un prejuicio y no en un peligro real.

\section{Situación a nivel comparado}

Más allá de las discrepancias académicas que puedan existir en torno a la inclusión electoral de las personas con discapacidad mental, los instrumentos internacionales sobre el particular no proscriben categóricamente la interdicción por demencia en sí misma ni tampoco que se le asignen efectos electorales. En este sentido, el art. 12 № 2 CNUDPD establece el deber de los Estados Partes de reconocer "que las personas con discapacidad tienen capacidad jurídica en igualdad de condiciones con las demás en todos los aspectos de la vida". No obstante, el № 4 del mismo artículo agrega que se debe asegurar "que en todas las medidas relativas al ejercicio de la capacidad jurídica se proporcionen salvaguardias adecuadas y efectivas para impedir los abusos de conformidad con

\footnotetext{
${ }^{61}$ LOPEZ-GUERRA (2014), p. 66.

${ }^{62}$ BECKMAN (2009), p. 156.

${ }^{63}$ BECKMAN (2009), p. 156.

${ }^{64}$ BECKMAN (2009), p. 162.

${ }^{65}$ AGRAN et al. (2015), p. 61; REDLEY (2008), p. 383.

${ }^{66}$ REDLEY (2008), p. 383.

${ }^{67}$ BARCLAY (2013), p. 157.
} 
el derecho internacional en materia de derechos humanos". Asimismo, se debe garantizar que tales medidas

respeten los derechos, la voluntad y las preferencias de la persona, que no haya conflicto de intereses ni influencia indebida, que sean proporcionales y adaptadas a las circunstancias de la persona, que se apliquen en el plazo más corto posible y que estén sujetas a exámenes periódicos por parte de una autoridad o un órgano judicial competente, independiente e imparcial.

Como corolario, de adoptarse una medida que afecte la capacidad jurídica de una persona con discapacidad mental, aquella debe satisfacer una serie de estándares consistentes con el modelo social de discapacidad, entre los cuales destaca el de proporcionalidad.

Una primera proyección de este estándar puede verse en la declaración interpretativa emitida el año 2010 del "Código de Buenas Prácticas en Materia Electoral, Directrices Informe Explicativo" adoptado por la Comisión de Venecia en 2002. Dicha declaración, en directa referencia al art. 29 CNUDPD, clarifica la posición de la Comisión respecto de las restricciones al derecho de sufragio asociadas a la pérdida de la capacidad de ejercicio. En ella se sostiene que las personas con discapacidad mental demostradas "pueden" ser privadas del derecho a voto, a condición de que ello sea consecuencia de una decisión individual de una corte y no el efecto automático de la pérdida de la capacidad de ejercicio ${ }^{68}$.

En este mismo orden de ideas, en el fallo Alajos Kiss v. Hungría ${ }^{69}$, el Tribunal Europeo de Derechos Humanos advirtió que la legislación húngara sobre restricciones al derecho a sufragio de personas con discapacidad mental no ponderaba adecuadamente los diversos intereses afectados ni consideraba una evaluación de la proporcionalidad de la restricción ${ }^{70}$. Agregó que

si una restricción de derechos fundamentales aplica a un grupo particularmente vulnerable de la sociedad que han sufrido considerable discriminación en el pasado, tales como los discapacitados mentales, entonces el margen de apreciación del Estado es sustancialmente más estrecho y debe tener razones de mucho peso para las restricciones en cuestión ${ }^{71}$.

El Tribunal concluyó que "una privación indiscriminada del derecho a sufragio sin una evaluación judicial individualizada y únicamente en una discapacidad mental que requiere una guarda parcial no puede ser considerada compatible con los legítimos fundamentos para restringir el derecho a voto"72.

En sentido análogo se ha pronunciado la Corte Suprema de Justicia de la Nación de $\operatorname{Argentina}^{73}$. Así, ha declarado que la restricción al derecho de sufragio contemplada en el Código Nacional Electoral derivada de la declaración judicial de incapacidad de una persona "debe aplicarse de acuerdo con los principios y garantías que rigen para las personas con discapacidad e impone una evaluación pormenorizada y específica sobre la capacidad para votar"74. Este fallo parte del supuesto de que el derecho a voto de las personas con discapacidad mental no es absoluto y puede estar sujeto a restricciones. Sin embargo, tales restricciones deben apartarse del modelo de

${ }^{68}$ COMISIÓN EUROPEA PARA LA DEMOCRACIA POR EL DERECHO (COMISIÓN DE VENECIA) (2002), p. 5.

${ }^{69}$ Tribunal Europeo de Derechos Humanos, № 38832/06, 20 de mayo de 2010, párr. 42. Este razonamiento fue luego reiterado en Tribunal Europeo de Derechos Humanos, № 62924/10, 23 de septiembre de 2014.

${ }^{70}$ Tribunal Europeo de Derechos Humanos, № 38832/06, 20 de mayo de 2010, párr. 41.

${ }^{71}$ Tribunal Europeo de Derechos Humanos, № 38832/06, 20 de mayo de 2010, párr. 42.

72 Tribunal Europeo de Derechos Humanos, № 38832/06, 20 de mayo de 2010, párr. 42.

${ }^{73}$ Corte Suprema de Justicia de la Nación Argentina, CIV 83563/I997/CSI, 10 de julio de 2018.

${ }^{74}$ Corte Suprema de Justicia de la Nación Argentina, CIV 83563/I997/CSI, 10 de julio de 2018, c. 8o. 
incapacitación con sustitución de voluntad y ajustarse a las exigencias del modelo social de discapacidad. Por consiguiente, la pérdida del derecho a sufragio no puede ser la consecuencia automática de una declaración general de incapacidad. Antes bien, se debe concluir que la persona afectada

carec[e] de capacidad para realizar ese acto político específico, a través de evaluaciones que brindaran las razones concretas por las cuales no se encontraba en condiciones de ejercer su derecho al sufragio de manera autónoma, es decir, que no podía votar ni aun con alguna medida de apoyo que lo permitiera sin sustituir su voluntad ${ }^{75}$.

De momento, el sistema chileno de privación del derecho a sufragio como consecuencia inmediata de la pérdida de la capacidad civil sigue siendo el más difundido, sea en virtud de una norma constitucional o legal. Sistemas de similares características pueden encontrarse también en Alemania, Bélgica, Bulgaria, Chipre, Costa Rica, Dinamarca, Eslovaquia, Estonia, Grecia, Irlanda, Lituania, Luxemburgo, Macedonia, Malta, Nicaragua, Polonia, Portugal, Rumania, Serbia, entre otros $^{76}$. Sin perjuicio de ello, las declaraciones y fallos aquí referidos dan testimonio de una emergente tendencia internacional en orden a desligar la capacidad patrimonial del ejercicio del derecho a sufragio. Es en este contexto que algunos países han subordinado el ejercicio del derecho a sufragio de las personas con discapacidad mental privadas de capacidad jurídica patrimonial a una evaluación separada y específica de su habilidad para votar, tal como ocurre en Hungría y Eslovenia, Francia y República Checa ${ }^{77}$.

Sin perjuicio de lo anterior, el ACNUDH ha advertido que el art. 29 CNUDPD

no prevé restricciones razonables ni permite excepción alguna aplicable a grupos de personas con discapacidad. Por lo tanto, cualquier exclusión o restricción del derecho de voto por motivos de discapacidad psicosocial o intelectual real o percibida constituirá una 'discriminación por motivos de discapacidad' a tenor de lo dispuesto en el artículo 2 de la Convención ${ }^{78}$.

Esta afirmación sugiere que ni siquiera los sistemas de evaluación de capacidad electoral para cada caso concreto superarían los estándares de la CNUDPD. En definitiva, de acuerdo con este planteamiento, correspondería desligar enteramente la capacidad de ejercicio del derecho a sufragio. Así ha ocurrido en países como Alemania, Austria, Canadá, Croacia, Dinamarca, Eslovaquia, España, Finlandia, Italia, Letonia, los Países Bajos, Suecia y el Reino Unido.

Respecto del modo concreto en que las personas con discapacidad mental ejercerían su derecho a sufragio, se reconocen a lo menos tres fórmulas, no necesariamente excluyentes entre sí, disponibles a nivel comparado. Una primera alternativa consiste en que dichas personas ejerzan su derecho a voto de manera presencial en las cámaras dispuestas en los recintos comunes de votación. Este sistema opera en España, donde adicionalmente los votantes pueden designar a una persona para que les asista en la emisión de su voto, y en los Países Bajos, donde no se contempla tal posibilidad ${ }^{79}$. La segunda opción consiste en habilitar cámaras especiales de votación al interior de hospitales u otras instituciones de cuidado de personas con discapacidad mental. Esta modalidad

\footnotetext{
${ }^{75}$ Corte Suprema de Justicia de la Nación Argentina, CIV 83563/I997/CSI, 10 de julio de 2018, c. 9‥

${ }^{76}$ FRA (2014), p. 41.

77 FRA (2014), p. 41. Con todo, se discute el potencial carácter discriminatorio de esta clase de evaluaciones. BECKMAN (2014), p. 230; KOPEL (2017), pp. 238-241; REDLEY (2008), p. 382.

${ }^{78}$ CONSEJO DE DERECHOS HUMANOS (2011), p. 8, párr. 29.

${ }^{79}$ VAN HEES et al. (2018).
} 
ha sido implementada, por ejemplo, en Irlanda ${ }^{80}$. En tercer y último lugar, el derecho a sufragio de personas con discapacidad mental se puede ejercer mediante el voto anticipado, en modalidad presencial, como ocurre en Alemania y en Suiza, o por vía postal, como en el caso de Canadá y Finlandia ${ }^{81}$. Es del caso señalar que, en esos países, esta opción se encuentra disponible para todos los votantes, no solo para aquellos con discapacidades.

Ciertamente estas diversas fórmulas de ejercicio del derecho a sufragio admiten matices o variantes en su diseño e implementación, cuestión que podría analizarse con más detalle en un trabajo de mayor extensión a desarrollar a futuro. Por lo pronto, los ejemplos propuestos permiten apreciar que existen diversas alternativas para dotar de efectividad al derecho de participación de las personas con discapacidades mentales. Es importante subrayar que el éxito de cualquiera de dichas fórmulas -en términos de su contribución efectiva a una participación significativadepende de la adopción de otras medidas de accesibilidad. Entre ellas pueden mencionarse, información electoral y papeletas de votación de fácil lectura y comprensión, campañas públicas de información y sensibilización sobre los derechos de las personas con discapacidad, capacitaciones a quienes ejerzan funciones públicas en los procesos electorales, etc. ${ }^{82}$.

Para cerrar este apartado, cabe añadir que las Observaciones finales sobre el informe inicial de Chile del Comité sobre los Derechos de las Personas con Discapacidad reflejan una preocupación por el hecho de que "la declaratoria de interdicción sea impedimento para que una persona con discapacidad pueda ejercer su derecho al voto y a la participación política". A lo anterior se agrega una recomendación de "la revisión del registro electoral para garantizar que no se prive del derecho a voto a ninguna persona por razón de un impedimento o por limitaciones en su capacidad jurídica"83. De cara a estas observaciones, una eventual incorporación de Chile a la nómina de países que reconoce plena capacidad electoral a las personas con discapacidad mental no parece tan lejana después de todo.

\section{Voto asistido y autonomía}

A pesar de la incipiente tendencia comparada en orden a disminuir o eliminar las restricciones al derecho a sufragio de las personas con discapacidad mental, no puede obviarse que algunas de estas personas pueden tener dificultades para ejercer este derecho por sí solas. Precisamente, en reconocimiento de esta realidad, el propio art. 29 letra a) literal iii CNUDPD consagra

[l]a garantía de la libre expresión de la voluntad de las personas con discapacidad como electores y a este fin, cuando sea necesario y a petición de ellas, permitir que una persona de su elección les preste asistencia para votar.

En esta misma línea de ideas, el art. 61 inc. 3o de la Ley № 18.700 orgánica constitucional sobre votaciones populares y escrutinios ${ }^{84}$ establece que

\footnotetext{
${ }^{80}$ KELLY (2014).

81 GARNETT (2019).

82 Ejemplos de esta clase de medidas pueden encontrarse en CONSEJO DE DERECHOS HUMANOS (2011), pp. 12-14.

${ }^{83}$ COMITÉ SOBRE LOS DERECHOS DE LAS PERSONAS CON DISCAPACIDAD (2016), p. 9.

${ }^{84}$ Ley Nº 18.700, de 1988.
} 
las personas con alguna discapacidad que les impida o dificulte ejercer el derecho de sufragio, podrán ser acompañadas hasta la mesa por otra persona que sea mayor de edad, y estarán facultadas para optar por ser asistidas en el acto de votar.

En consecuencia, al momento de votar, ellas pueden decidir si necesitan o no ser asistidas por alguien mayor de edad, que sea de su confianza, y comunicar esta decisión al presidente de la mesa en que le corresponde sufragar.

Dado que la disposición transcrita no distingue según el tipo de discapacidad, el voto asistido no solo está dirigido a personas con discapacidad física, sino también a personas con discapacidad mental y por ello es objeto de interés para efectos de esta investigación. La incorporación del voto asistido al derecho chileno sin duda alguna constituye un avance en orden a la inclusión electoral de estas personas y desde ese punto de vista debe ser celebrada. Pero, desde otro punto de vista, cabe preguntarse si en la configuración normativa de esta figura se ha considerado suficientemente la clase de barreras materiales que ellas suelen enfrentar a la hora de emitir su voto. La cuestión surge en atención a que las discapacidades mentales no siempre son visibles o fácilmente perceptibles y a que pueden expresarse en una amplia variedad de comportamientos y actitudes ${ }^{85}$.

Así, por ejemplo, la ley no prevé la preferencia de los electores discapacitados para acceder a la mesa receptora de sufragios. En la práctica, es posible otorgar tal preferencia si así lo acuerda la mesa y si ningún elector se opone ${ }^{86}$. Otra situación por considerar dice relación con la ampliación del tiempo para votar ${ }^{87}$. De acuerdo con el art. 64 inc. 20 de la Ley № 18.700, “[e]l elector entrará en la cámara secreta y no podrá permanecer en ella más de un minuto, salvo las personas con discapacidad, quienes podrán emplear un tiempo razonable". Piénsese, por último, en la posibilidad de sufragar fuera de la cámara, también contemplada en el art. 64 inc. 2o de la Ley № 18.700. Conforme a esta norma "[s]ólo en casos de personas con discapacidad que no puedan ingresar a la cámara, la Mesa podrá aceptar que sufraguen fuera de ella, pero adoptando todas las medidas que fueren conducentes a mantener el secreto de su votación".

Peor aún, es posible que surjan dudas respecto de la existencia misma de la discapacidad o de su alcance $y$, por consiguiente, de la procedencia del derecho a asistencia. La propia Ley № 18.700 se sitúa en tal hipótesis. Sobre el particular expresa el art. 61 inc. 1o: "[e]n caso de duda respecto de la naturaleza de la discapacidad del sufragante, el presidente consultará a los vocales para adoptar su decisión final". Dicho de otro modo, el presidente de la mesa y los vocales de esta podrían negar la asistencia si a su juicio, la persona que la solicita no sufre de una discapacidad o esta no es de una entidad tal que amerite la asistencia de otros para la emisión del voto ${ }^{88}$.

En suma, las facilidades o ajustes expuestos son a todas luces adecuados para asegurar el ejercicio del derecho a voto de personas con discapacidades físicas, pero no necesariamente para

\footnotetext{
85 DEPARTAMENTO DE EVALUACIÓN DE LA LEY. CÁMARA DE DIPUTADOS DE CHILE (2013), p. 2.

${ }^{86}$ Así lo indica el sitio web del Servicio Electoral, órgano constitucional autónomo encargado, entre otras cosas, de la administración, supervigilancia y fiscalización de los procesos electorales y plebiscitarios. Disponible en: https://www.servel.cl/preguntas-frecuentes/ [visitado el 11 de diciembre de 2018].

87 KARLAN (2007), p. 921.

${ }^{88}$ En concordancia con este planteamiento puede verse el Plan Nacional de sobre Inclusión Social de Personas en situación de Discapacidad de la Comisión Asesora Presidencial sobre Inclusión Social de Personas en Situación de Discapacidad. En dicho documento se plantea que "[d]esde 2012, no se registran datos sobre discapacidad en los registros electorales. Por lo tanto, no se puede evaluar si hay factores de discriminación en el ejercicio del derecho a voto. Esto es especialmente preocupante por la facultad discrecional de los vocales de mesa de rechazar personas por su 'apariencia'. No existe fiscalización de esta facultad a menos que sea por parte de los observadores de los partidos políticos, a saber, los apoderados de mesa, quienes no tienen instructivos al respecto". En concreto, la propuesta de la Comisión es que la fiscalización de estas prácticas quede entregada a SENADIS o al INDH. COMISIÓN ASESORA PRESIDENCIAL SOBRE INCLUSIÓN SOCIAL DE PERSONAS EN SITUACIÓN DE DISCAPACIDAD (2016), pp. 106 y 159.
} 
asegurar el ejercicio de este derecho a las personas con discapacidades mentales ${ }^{89}$. Para estas últimas, sus respectivas condiciones pueden ir asociadas a trastornos de ansiedad como fobias sociales, agorafobia, claustrofobia, trastorno obsesivo compulsivo, trastorno de ansiedad generalizada, trastorno de pánico, entre otros. En tales casos, es razonable suponer que pudieran requerir de acomodaciones como las señaladas. Sin embargo, dado que se trata de trastornos no fácilmente perceptibles y que la calificación de si el tipo de discapacidad amerita otorgar la facilidad corresponde a los integrantes de la mesa, quienes no son expertos en psiquiatría, su aplicación podría resultar ilusoria. La cuestión no es trivial desde una perspectiva jurídica, ya que la CNUDPD también consagra "[I]a garantía de que los procedimientos, instalaciones y materiales electorales sean adecuados, accesibles y fáciles de entender y utilizar".

Más generalmente, se han formulado cuestionamientos al carácter asistencialista mismo del voto asistido, el cual ha sido comparado con la promoción de baños asistidos para personas con discapacidades, a falta de baños accesibles ${ }^{90}$. Por ello, el Estado debería promover sistemas de votación accesibles y universales, que en la medida de lo posible puedan ser utilizados de manera autónoma, sin necesidad de recurrir a la caridad familiar o al buen criterio de otros votantes ${ }^{91}$. En este punto, los sistemas de voto en ausencia -como el voto postal, el establecimiento de sitios especiales votación en hospitales e instituciones similares ${ }^{92}$ o el voto electrónico- pueden ser de particular utilidad ${ }^{93}$. Y es que un régimen electoral que se tome en serio la inclusión y que es sensible a las específicas necesidades de los grupos vulnerables requiere ser complementado por otras formas de sufragio, en adición al tradicional voto presencial.

A la luz de todo lo dicho puede constatarse que, aun en un hipotético escenario en que se reconociera la plena capacidad electoral de las personas con discapacidad mental, el derecho chileno todavía tendría un buen trecho que avanzar en orden a su plena inclusión democrática. No puede negarse que la incorporación de la CNUDPD al ordenamiento chileno y la expedición de legislación para su implementación representan una evolución positiva. Con todo, subsisten trabas jurídicas y materiales para el efectivo ejercicio del derecho de sufragio de las personas con discapacidad mental que deben ser derribadas. Lo que está en juego no es tan solo la legitimidad del sistema democrático. Está también en juego la autoestima ${ }^{94}$, la aceptación e integración social ${ }^{95}$, el empoderamiento ${ }^{96}$ y la protección de los intereses y derechos ${ }^{97}$ de uno de los grupos más estigmatizados y vulnerables de las sociedades contemporáneas.

\footnotetext{
${ }^{89}$ El punto es puesto de relieve en términos genéricos, más allá del caso chileno, en KARLAWISH et al. (2004), p. 1347; KEELEY et al. (2008), p. 176

${ }^{90}$ Así lo sostuvo el presidente de la Fundación Nacional de Discapacitados, cuando se introdujo en Chile el voto asistido. HERNÁNDEZ (2018).

${ }^{91}$ Bajo esta óptica, se ha enfatizado que estos actores privados actúan como guardianes del mundo exterior para las personas con discapacidad mental, de modo tal que la incapacidad de estas para participar plenamente en el proceso electoral no solo resulta de la acción estatal, sino también privada. KARLAN (2007), p. 923; SCHUR Y ADYA (2013), p. 21.

${ }^{92}$ En efecto, no debe menospreciarse el rol que los cuidadores de las personas con discapacidad mental en estos recintos podrían tener en la promoción de sus inquietudes electorales. BECKMAN (2009), p. 164; BECKMAN (2007), p. 20; KARLAWISH et al. (2004), p. 1347; OKWEREKWU et al. (2018), pp. 4-5.

${ }^{93}$ BELT (2016), p. 1517; FRIEDMAN Y RIZZOLO (2017), p. 350. En tono crítico frente a los riesgos que plantean los sistemas de voto en ausencia, por contraste, KARLAWISH et al. (2004), pp. 1348-1349; SCHUR et al. (2017), pp. 12-15.

${ }^{94}$ SCHRINER et al. (1997), p. 96.

${ }^{95}$ NASH (2002); OKWEREKWU (2014).

${ }^{96}$ FRIEDMAN (2016), p. 10.

${ }^{97}$ KELLY (2014), p. 226.
} 


\section{Conclusiones}

La presente investigación se ha dedicado al estudio de la inclusión electoral de las personas con discapacidad mental en Chile. La inquietud por este tópico surge ante dos constataciones. La primera, es que en Chile se encuentra vigente una serie de instrumentos jurídicos internacionales y nacionales relativos a la promoción de la plena inclusión de las personas con discapacidades en todos los ámbitos de la vida social, lo cual ciertamente comprende la participación democrática de tales personas. La segunda, es que hay ciertas instituciones que, en su configuración por el derecho chileno, suscitan dudas respecto de su compatibilidad con los instrumentos antes aludidos. Dichas instituciones corresponden a la suspensión del derecho de sufragio de las personas con discapacidad mental como efecto de una declaración judicial de interdicción por demencia y el voto asistido de las personas con discapacidad.

Por lo que respecta a la suspensión del derecho a sufragio, se advierte que esta clase de práctica se encuentra alineada con diversos argumentos tradicionalmente esgrimidos para justificar la exclusión electoral de personas con discapacidad mental. Dichos argumentos, en esencia, apuntan a su incapacidad para tomar decisiones racionales, al peligro de que arruinen los resultados o comprometan la integridad de las elecciones y a la necesidad de transmitir un mensaje público sobre la importancia y seriedad de los procesos electorales. Los mismos representan la visión doctrinaria predominante en Chile y algunos de ellos fueron considerados de manera explícita en el debate relativo a los alcances de la mentada suspensión.

Sin perjuicio de lo anterior, cierta literatura médica, política y jurídica reciente ha adoptado un enfoque diverso. Ella ha procurado controvertir la solidez de las premisas teóricas en que reposan aquellos argumentos o refutarla con evidencia empírica respecto de las actitudes, capacidades y prácticas reales de estas personas. Esta última postura académica, a su vez, encuentra un correlato en una todavía incipiente, pero creciente, tendencia comparada en orden a suprimir o reducir las restricciones al derecho de sufragio de las personas con discapacidad mental. Estos desarrollos dogmáticos y prácticos revelan un progresivo cambio de paradigma, centrado en la autonomía y en el reconocimiento de la calidad de ciudadanas y de titulares de derechos de estas personas, incluyendo - muy, por cierto- sus derechos políticos.

No puede pasarse por alto, sin embargo, que ciertas personas con discapacidad mental pueden tener dificultades para ejercer sus derechos por sí solas y que pueden requerir facilidades o la asistencia de otros. Y es aquí donde entra en discusión la otra institución objeto de interés de esta investigación: el voto asistido. Pues bien, sin desconocer el significativo avance que dicha institución representa en el marco de la lucha por la inclusión de grupos típicamente marginados de los procesos electorales, su configuración en el derecho chileno amerita algunas observaciones críticas. El reproche apunta a que la misma está diseñada para discapacidades físicas o mentales claramente perceptibles y a que ciertos aspectos de su aplicación quedan entregados al criterio no experto de otros ciudadanos que ejercen un rol público en los procesos electorales.

Queda mucho por hacer en el camino hacia la plena inclusión electoral de las personas con discapacidad mental. Otros países ya han dado algunos pasos considerables y dan señas de la dirección a seguir. Por el momento es incierto si Chile se unirá a ellos o no y, en lo inmediato, no hay muestras masivas de preocupación por el tópico a nivel doctrinario o político. En este contexto, la presente investigación aspira a contribuir a visibilizar esta problemática y a promover su debate crítico. Con ello, podría mejorarse significativamente la calidad del sistema democrático y la calidad de vida de los integrantes de un grupo social históricamente marginado, minusvalorado y desaventajado. 


\section{BIBLIOGRAFÍA CITADA}

AGRAN, M. Y HUGHES, C. (2013): “'You can't vote-you're mentally incompetent': Denying democracy to people with severe disabilities", en: Research and Practice for Persons with Severe Disabilities (Vol. 38 , № 1), pp. 58-62.

AGRAN, M., MACLEAN, W. Y ANDREN, K. A. K. (2015): “I never thought about it': Teaching people with intellectual disability to vote", en: Education and Training in Autism and Developmental Disabilities (Vol. 50, № 4), pp. 388-396.

APPELBAUM, S., BONNIE, R. J. Y KARLAWISH, J. H. (2005): "The capacity to vote of persons with Alzheimer's disease", en: American Journal of Psychiatry (Vol. 162, № 11), pp. 2094-2100.

BACH, M. Y KERZNER, L. (2010): "A New Paradigm for Protecting Autonomy and the Right to Legal Capacity: Advancing Substantive Equality for Persons with Disabilities through Law, Policy and Practice". Disponible en: disabilities-commissioned-paper-bach-kerzner.pdf [visitado el 15 de octubre de 2018].

BARCLAY, L. (2013): “Cognitive Impairment and the Right to Vote: A Strategic Approach", en: Journal of Applied Philosophy (Vol. 30, № 2), pp. 146-159.

BCN (S. F.): "Historia de la Ley: Constitución Política de la República de Chile de 1980: Artículo 16: Causales de Suspensión del Derecho de Sufragio". Disponible en: https://www.leychile.cl/Navegar/scripts/obtienearchivo?id=recursoslegales/10221.3/3763/2/Tom o_II_Comision_Ortuzar.pdf [visitado el 26 de noviembre de 2018].

BECKMAN, L. (2007): "Political equality and the disenfranchisement of people with intellectual impairments", en: Social Policy and Society (Vol. 6, № 1), pp. 13-23.

Macmillan).

(2009): The Frontiers of Democracy: The Right to Vote and its Limits (London, Palgrave

(2014): "The accuracy of electoral regulations: The case of the right to vote by people with cognitive impairments", en: Social Policy and Society (Vol. 13, № 2), pp. 221-233.

BELL, D. M., MCKAY, C. Y PHILLIPS, K. J. (2001): “Overcoming the barriers to voting experienced by people with learning disabilities", en: British Journal of Learning Disabilities (Vol. 29, № 4), pp. 122-127.

BELT, R. (2016): “Contemporary voting rights controversies through the lens of disability", en: Stanford Law Review (Vol. 68), pp. 1491-1550.

BHUGRA, D., PATHARE, S., GOSAVI, C., VENTRIGLIO, A., TORALES, J., CASTALDELLI-MAIA, J., TOLENTINO, E. J. L. Y NG, R. (2016): "Mental illness and the right to vote: a review of legislation across the world", en: International Review of Psychiatry (Vol. 28, № 4), pp. 1-5. 
BULlenkAMP, J. Y VOGES, B. (2004): "Voting Preferences of Outpatients with Chronic Mental Illness in Germany", en: Psychiatric Services (Vol. 55, № 12), pp. 1440-1442.

CLARO SOLAR, L. (1992): Explicaciones de Derecho Civil chileno y comparado (Santiago, Editorial Jurídica de Chile), tomo V.

COHEN, C. (1975): “On the Child's Status in the Democratic State: A Response to Mr. Schrag", en: Political Theory (Vol. 3, № 4), pp. 458-463.

COMISIÓN ASESORA PRESIDENCIAL SOBRE INCLUSIÓN SOCIAL DE PERSONAS EN SITUACIÓN DE DISCAPACIDAD (2016): "Plan Nacional sobre Inclusión Social de Personas en Situación de Discapacidad". Disponible en: https://www.google.com/url?sa=t\&rct=j\&q=\&esrc=s\&source=web\&cd=1\&cad=rja\&uact=8\&ved=2 ahUKEwiigbyj_JvIAhUJGbkGHQIBCEsQFjAAegQIAxAC\&url=https\%3A\%2F\%2Fwww.senadis.gob.cl\% 2Fdescarga\%2Fi\%2F633\%2Fdocumento\&usg=AOvVaw3APEQar90mPs5mEgE5aOiW [visitado el 14 de octubre de 2018].

COMISIÓN EUROPEA PARA LA DEMOCRACIA POR EL DERECHO (COMISIÓN DE VENECIA) (2006): “Código de Buenas Prácticas en Materia Electoral, Directrices Informe Explicativo, 2002". Disponible en: https://www.venice.coe.int/webforms/documents/default.aspx?pdffile=CDL-AD(2002)023rev-spa [visitado el 04 de noviembre de 2018].

COMITÉ SOBRE LOS DERECHOS DE LAS PERSONAS CON DISCAPACIDAD (2016): "Observaciones finales sobre el informe inicial de Chile". Disponible en: http://acnudh.org/comite-sobre-los-derechos-de-laspersonas-con-discapacidad-crc/ [visitado el 14 de octubre de 2018].

CONSEJO DE DERECHOS HUMANOS, ONU (2011): "Estudio temático preparado por la Oficina del Alto Comisionado de las Naciones Unidas para los Derechos Humanos sobre la participación de las personas con discapacidad en la vida política y pública, A/HRC/19/36, 21/12/2011". Disponible en: https://www.google.com/url?sa=t\&rct=j\&q=\&esrc=s\&source=web\&cd=1\&cad=rja\&uact=8\&ved=2 ahUKEwjEjqPBqTfAhXEHpAKHe8fBukQFjAAegQIAxAC\&url=https\%3A\%2F\%2Fwww.ohchr.org\%2FDocuments\%2FI ssues\%2FDisability\%2FSubmissionThematicStudy\%2FA.HRC.19.36_sp.doc\&usg=AOvVaw2TZWLD_ FSHROizsQCjHLkV [visitado el 14 de octubre de 2018].

DAHL, R. (1992): La democracia y sus críticos (Barcelona, Paidós).

DAMORE, D. F., WATERS, M. M. Y BOWLER, S. (2012): “Unhappy, Uninformed, or Uninterested? Understanding 'None of the Above' Voting”, en: Political Research Quarterly (Vol. 65, № 4), pp. 895907.

DEPARTAMENTO DE EVALUACIÓN DE LA LEY. CÁMARA DE DIPUTADOS DE CHILE (2012): “Evaluación de la Ley № 20.422, 2012". Disponible en: http://www.evaluaciondelaley.cl/foro_ciudadano/site/artic/20121012/asocfile/20121012101200/ informe_final_ley_20422_27_dic_.pdf [visitado el 03 de noviembre de 2018]. 
(2013): “Evaluación de la Ley № 18.600, 2013". Disponible en: https://www.camara.cl/camara/media/docs/informe_ley18600.pdf [visitado el 03 de noviembre de 2018].

DONALDSON, S. Y KYMLICKA, W. (2017): "Rethinking Membership and Participation in an Inclusive Democracy: Cognitive Disability, Children, Animals", en: Arneil, B. y Hirschmann, N. J. (Eds.), Disability and Political Theory (Cambridge, Cambridge University Press), pp. 168-197.

DRISCOLL, A. Y NELSON, M. J. (2014): "Ignorance or Opposition? Blank and Spoiled Votes in LowInformation, Highly Politicized Environments", en: Political Research Quarterly, pp. 1-15.

FINKELSTEIN, V. (1980): Attitudes and disabled people (New York, World Rehabilitation Fund).

FRA (2014): "The right to political participation for persons with disabilities: human rights indicators". Disponible en: http://fra.europa.eu/en/publication/2014/right-political-participation-personsdisabilities-human-rights-indicators [visitado el 11 de octubre de 2018].

FRIEDMAN, C. (2016): “'Every Vote Matters:' Experiences of People with Intellectual and Developmental Disabilities in the 2016 United States General Election”, en: Review of Disability Studies (Vol. 14, № 1), pp. 1-13.

FRIEDMAN, C. Y RIZZOLO, M. C. (2017): “Correlates of voting participation of people with intellectual and developmental disabilities", en: Journal of Social Work in Disability \& Rehabilitation (Vol. 16, № 34), pp. 347-360.

GARNETT, H. A. (2019): Early Voting: "Comparing Canada, Finland, Germany, and Switzerland", en: Election Law Journal (Vol. 18, N²), pp. 116-131.

GONZÁLEZ PAINEMAL, V. (2018): "Interdicción por demencia y otras restricciones a la capacidad jurídica de las personas con discapacidad intelectual y mental, bajo la mirada de la CRPD", en: Revista SOLONIK Políticas Públicas y Derechos Humanos (№ 3), pp. 101-120.

GREEN, B. G. Y KLEIN, N. (1980): "The mentally retarded and the right to vote", en: Polity (Vol. 13, № 2), pp. 184-206.

HERNÁNDEZ, A. (2008): “Discapacitados: voto 'asistido' o inducido". Disponible en: http://www.fnd.cl/votoasistidooinducido.html [visitado el 10 de diciembre de 2018].

HURME, S. B. Y APPELBAUM, S. (2007): "Defining and Assessing Capacity to Vote: The Effect of Mental Impairment on the Rights of Voters", en: McGeorge Law Review (Vol. 38, № 4), pp. 931-1014.

KARLAN, P. S. (2007): "Framing the Voting Rights Claims of Cognitively Impaired Individuals", en: McGeorge Law Review (Vol. 38), pp. 917-950. 
KARLAWISH, J., BONNIE, R. J., APPELBAUM, P. S., LYKETSOS, C., JAMES, B., KNOPMAN, D., PATUSKY, C., KANE, R. A. Y KARLAN, P. S. (2004): "Addressing the ethical, legal, and social issues raised by voting by persons with dementia", en: Journal of the American Medical Association (Vol. 292, № 11), pp. 1345-1350.

KEELEY, H., REDLEY, M., HOLLAND, A. J. Y CLARE, I. C. H. (2008): "Participation in the 2005 general election by adults with intellectual disabilities”, en: Journal of Intellectual Disability Research (Vol. 52, № 3), pp. 175-181.

KELLY, B. D. (2014): "Voting and mental illness: the silent constituency", en: Irish Journal of Psychological Medicine (Vol. 31), pp. 225-227.

KLEIN, M. M. Y GROSSMAN, S. A. (1971): "Voting competence and mental illness", en: American Journal of Psychiatry (Vol. 127, № 11), pp. 1562-1565.

KOPEL, C. (2017): "Suffrage for People with Intellectual Disabilities and Mental Illness: Observations on a Civic Controversy", en: Yale Journal of Health Policy, Law, and Ethics (Vol. 17, № 1), pp. $209-250$.

LLEWELYN, A. Y HOGAN, K. (2000): "The Use and Abuse of Models of Disability", en: Disability \& Society (Vol. 15, $\left.N^{\circ} 1\right)$, pp. 157-165.

LOPEZ-GUERRA, C. (2012): "Enfranchising minors and the mentally impaired", en: Social Theory and Practice (Vol. 38, № 1), pp. 115-138.

(2014): "Democracy and Disenfranchisement: The Morality of Electoral Exclusions" (Oxford, Oxford University Press).

LYON PUELMA, A. (2007): Personas naturales (Santiago, Ediciones Universidad Católica de Chile).

MARSHALL, P. (2019): “Derecho a sufragio", en: Contreras, P. y Salgado C. (Eds.), Derechos fundamentales: derechos civiles y políticos (en prensa).

MARKS, D. (1997): “Models of disability”, en: Disability and Rehabilitation (Vol. 19, N³), pp. 85-91.

MUNN, N. (2014): “Capacity Testing as a Means of Increasing Political Inclusion”, en: Democratization (Vol. 21, № 6), pp. 1134-1152.

NASH, M. (2002): "Voting as a Means of Social Inclusion for People with a Mental Illness", en: Journal of Psychiatric \& Mental Health Nursing (Vol. 9), pp. 697-703.

NOGUEIRA ALCALÁ, H. (2012): Derecho Constitucional Chileno (Santiago, Thomson Reuters), tomo I.

OKWEREKWU, J. A., MCKENZIE, J. B., YATES, K. A., SORRENTINO, R. M. Y FRIEDMAN, S. H. (2018): "Voting by People with Mental Illness", en: Journal of the American Academy of Psychiatry and the Law (Vol. 46, № 4), pp. 1-8.

OLIVER, M. (1990): The Politics of Disablement (London, Macmillan Education Ltd). 
REDleY, M., MAINA E., KEeling, A. Y PATTNI, P. (2012): "The Voting Rights of Adults with Intellectual Disabilities: Reflections on the Arguments, and Situation in Kenya and England and Wales", en: Journal of Intellectual Disability Research (Vol. 56, № 11), pp. 1026-1035.

REDLEY, M. (2008): "Citizens with learning disabilities and the right to vote", en: Disability and Society (Vol. 23, № 4), pp. 375-384.

SCHRINER, K., OCHS, L. A. Y SHIELDS, T. G. (1997): "The Last Suffrage Movement: Voting Rights for Persons with Cognitive and Emotional Disabilities", en: Publius (Vol. 27, № 3), pp. 75-96.

(2000): "Democratic dilemmas: Notes on the ADA and voting rights of people with cognitive and emotional impairments", en: Berkeley Journal of Employment and Labor Law (Vol. 21, № 1), pp. 437-472.

SCHUR, L. Y ADYA, M. (2013): "Sidelined or mainstreamed? Political participation and attitudes of people with disabilities in the United States", en: Social Science Quarterly (Vol. 94, № 3), pp. 1-29.

SCHUR, L., MASON, A. Y ADYA, M. (2017): "Disability, Voter Turnout, and Polling Place Accessibility", en: Social Science Quarterly (Vol. 98, № 5), pp. 1-17.

SILVA BARROILHET, P. (2017): La capacidad jurídica de las personas con discapacidad intelectual (Santiago, Thomson Reuters).

SILVA BASCUÑáN, A. (1997): Tratado de Derecho Constitucional (Santiago, Editorial Jurídica de Chile), tomo IV.

VAN HEES, S., BOEIJE, H. R. Y DE PUTTER, I. (2019): “Voting barriers and solutions: the experiences of people with disabilities during the Dutch national election in 2017", en: Disability \& Society (Vol. 34, № 5), pp. 819-836.

WALD, M. (1976): "Basic Personal and Civil Rights", en: Kindred, M. et al., The Mentally Retarded Citizen and the Law (New York, The Free Press), pp. 2-30.

WALDRON, J. (1998): "Participation: The Right of Rights", en: Proceedings of the Aristotelian Society, New Series (Vol. 98), pp. 307-337.

\section{JURISPRUDENCIA CITADA}

ALAJOS KISS V. HUNGRÍA, № 38832/06, Tribunal Europeo de Derechos Humanos, 20 de mayo de 2010.

GAJESI V. HUNGRÍA, № 62924/10, Tribunal Europeo de Derechos Humanos, 23 de septiembre de 2014.

CSJN “F., H. O. S/ ARTí́CULO 152 TER CÓDIGO CIVIL”, sentencia del 10 de julio de 2018, Fallos 341:745, en: www.csjn.gov.ar. 


\section{NORMAS JURÍDICAS CITADAS}

DECLARACIÓN UNIVERSAL DE DERECHOS HUMANOS, adoptada por la Asamblea General de las Naciones Unidas. Resolución 217 A (III), 10 de diciembre de 1948.

DECRETO № 99, promulga la Convención Interamericana para la Eliminación de Todas las Formas de Discriminación contra las Personas con Discapacidad. Diario Oficial, 20 de junio de 2002.

DECRETO № 100, fija el texto refundido, coordinado y sistematizado de la Constitución Política de la República de Chile. Diario Oficial, 22 de septiembre de 2005.

DECRETO № 201, promulga la Convención de las Naciones Unidas sobre los derechos de las personas con discapacidad y su protocolo facultativo. Diario Oficial, 17 de septiembre de 2008.

DECRETO № 873, aprueba Convención Americana sobre Derechos Humanos, denominada "Pacto de San José de Costa Rica". Diario Oficial, 05 de enero de 1991.

DFL № 1, fija el texto refundido, coordinado y sistematizado del Código Civil. Diario Oficial, 30 de mayo de 2000.

LEY № 20.609, establece medidas contra la discriminación. Diario Oficial, 24 de julio de 2012.

LEY N²0.422, establece normas sobre igualdad de oportunidades e inclusión social de las personas con discapacidad. Diario Oficial, 10 de febrero de 2010.

LEY N 18.700 , orgánica constitucional sobre votaciones populares y escrutinios. Diario Oficial, 06 de mayo de 1988.

LEY 18.600, establece Normas sobre Deficientes Mentales. Diario Oficial, 19 de febrero de 1987.

LEY № 1.552, Código de Procedimiento Civil. Diario Oficial, 30 de agosto de 1902.

PACTO INTERNACIONAL DE DERECHOS CIVILES Y POLÍTICOS, adoptado por la Asamblea General de las Naciones Unidas. Resolución 2200 A (XXI), 16 de diciembre de 1966.

PRINCIPIOS PARA LA PROTECCIÓN DE LOS ENFERMOS MENTALES Y EL MEJORAMIENTO DE LA ATENCIÓN DE LA SALUD MENTAL, adoptados por la Asamblea General de las Naciones Unidas. Resolución 46/119, 17 de diciembre de 1991. 